\title{
The protective effect of gentisic acid on rheumatoid arthritis via the RAF/ERK signaling pathway
}

\author{
Xiaojun Dong, Qi Zhang, Fujia Zeng, Mingxing Cai and Dou Ding*
}

\begin{abstract}
Background: RAF and ERK pathways are known to be activated in human rheumatoid arthritis (RA) fibroblast-like synoviocytes (FLS), which play an important role in the pathogenesis and destruction of RA. Gentisic acid (GA) was a natural product derived from plants, which has been reported can attenuate pressure overload-induced cardiac hypertrophy and fibrosis in mice through inhibition of the ERK1/2 pathway. Whether GA can inhibit the occurrence and development of RA through RAF/ERK signaling pathway has not been reported. The purpose of this study is to determine whether GA may have a certain therapeutic effect on RA-FLS.

Method: Bovine type Il collagen was used to establish a rat model of rheumatism. Enzyme-linked immunosorbent assay was used to detect inflammatory factors, anti-inflammatory mediators, and rheumatoid factor. Hematoxylin and eosin and TUNEL staining were used to detect the effect of GA on histochemical with rheumatoid arthritis. RAF, ERK, and p-ERK expressions in synovial tissue were measured by western blot and immunohistochemical. Besides, human rheumatoid arthritis fibroblast-like synoviocytes cell line MH7A was used to investigate the biological behavior influenced by GA. Apoptosis assay was performed to detect apoptosis of GA on MH7A cells. Transwell invasion assay was performed to detect the ability of cell migration.
\end{abstract}

Result: The result showed that GA could reduce joint swelling and inflammation. At the same time, it can also promote the apoptosis of synovial cells and down-regulate the RAF/ERK pathway.

Conclusion: GA may ameliorate inflammatory factors' abnormality, synovial hyperplasia, and apoptosis of synovium via inhibiting the RAF/ERK signaling pathway.

Keywords: Rheumatoid arthritis, Gentisic acid, FLS, RAF/ERK1/2

\section{Introduction}

Rheumatoid arthritis (RA) belongs to chronic autoimmune disease which has the main clinical manifestations of synovitis, cartilage damage, and symmetrical joint damage [1]. RA often occurs in small joints such as hands and feet, also involves other systems outside the joints, and even leads to joint deformities or loss of function

*Correspondence: dingdou2017@126.com

Traditional Chinese Medical Department of Zunyi Medical

and Pharmaceutical College, Zunyi 563006, Guizhou, China
[2]. The prevalence of rheumatoid arthritis is $5-10 \%$, and there are regional differences [3]. The incidence of RA is determined by environmental factors, genetic background, environment-genetic interaction, and epigenetic modification [4]. The functional disability of RA patients will reduce their working ability and social participation, increase medical costs, and further aggravate the social burden [1]. Therefore, this is a major social problem that needs to be solved urgently.

Increasing studies implicated that MAPK pathway is activated in RA [5]. The MAPKs pathway, a critical signaling pathway in the pathogenesis of RA, is activated in original author(s) and the source, provide a link to the Creative Commons licence, and indicate if changes were made. The images or other third party material in this article are included in the article's Creative Commons licence, unless indicated otherwise in a credit line to the material. If material is not included in the article's Creative Commons licence and your intended use is not permitted by statutory regulation or exceeds the permitted use, you will need to obtain permission directly from the copyright holder. To view a copy of this licence, visit http://creativecommons.org/licenses/by/4.0/. The Creative Commons Public Domain Dedication waiver (http://creativecommons.org/publicdomain/zero/1.0/) applies to the data made available in this article, unless otherwise stated in a credit line to the data. 
FLSs when stimulated by pro-inflammatory cytokines, such as TNF- $\alpha$ and IL-1 $\beta[6,7]$. FLS plays an important role in joint balance, which exhibits independent growth, abnormal proliferation, and erosion characteristics. Besides, RA-FLS can also secrete a variety of inflammatory cytokines, which interact with local infiltrating inflammatory cells and jointly participate in the joint destruction process of RA $[8,9]$. Rheumatoid factor (lgG, $\mathrm{RF}$ ) is an antibody against the Fc region of IgG and has been used as a diagnostic marker for rheumatoid arthritis [10]. Inhibition of the MAPK (RAF/ERK1/2) signaling pathway can suppress the proliferation, migration, and invasion of RA-FLSs [11].

Touguxiang (TGX) is a famous Traditional Chinese medicinal herb used for the treatment of rheumatoid arthritis. TGX is the whole plant or root of Gaultheria leucocarpa Bl. var. crenulata (Kurz) T. Z. Hsu, which can cure rheumatoid arthritis by reducing the concentration of $\mathrm{K}^{+}, \mathrm{DA}, \mathrm{NE}$, and 5-HT in joint fluid, and the content of PGE2 or LTB4 in serum [12,13]. Gentiolic acid (2,5-dihydroxybenzoic acid, GA) is the active ingredient of TGX, which can attenuate pressure overload-induced cardiac hypertrophy and fibrosis in mice through inhibition of the ERK1/2 pathway $[14,15]$. Although TGX has so many effects, it has not been reported whether it can regulate RA through the ERK pathway.

In this study, it discovered the therapeutic effect of GA on rheumatoid arthritis, explored its effect on the proliferation, apoptosis and aggressive behavior of FLSs in rheumatoid arthritis, and explored its potential mechanisms involved in the pathogenesis of rheumatoid arthritis.

\section{Materials and methods Animals and grouping}

32 male Wistar rats $(160 \pm 10 \mathrm{~g})$ were provided by the Chengdu Dashuo Experimental Animal Co. Ltd. The animal experiments were approved by the ethics committee of Traditional Chinese Medical Department of Zunyi Medical and Pharmaceutical College. The animal experiments meet the Canadian Council on Animal Care guidelines and National Academies Press (NAP) Guide for the Care and Use of Laboratory Animals. The rats eat and drink freely, the temperature is controlled at about $21{ }^{\circ} \mathrm{C}$, the humidity is about $50 \%$, the light is controlled for $12 \mathrm{~h}$ bright/12 $\mathrm{h}$ dark. Bovine type II collagen (BTII) (Chondrex, USA) was emulsified in complete Freund adjuvant (Sigma, USA) with the ratio of 1:1 to obtain a collagen emulsion. Except for the control group $(n=8)$, each rat was injected with $0.2 \mathrm{~mL}$ the mixture under the plantar fascia of the left hind foot to get the CIA rat model. The injection volume is $0.1 \mathrm{~mL} /$ mouse, and each animal is injected once $[16,17]$. On the 7 th day after the inflammation, the foot and plantar volume were measured. According to the different degree of plantar swelling, the rats were randomly divided into 3 groups, as the model group, GA low-dose (30 mg/kg), and high-dose group $(60 \mathrm{mg} / \mathrm{kg})$. On the 7 th-28th day after inflammation, the rats were given continuous intragastric administration once a day, and the normal group and the model group were given equal volumes of normal saline. On the 28th day, the rats were the animals were injected $1 \%$ sodium pentobarbital $(50 \mathrm{mg} / \mathrm{kg})$ and sacrificed by carbon dioxide inhalation to obtain tissue and blood.

\section{Enzyme-linked immunosorbent assay (ELISA)}

After resting at $4{ }^{\circ} \mathrm{C}$ for $10 \mathrm{~min}$, rat blood was centrifuged at $1000 \mathrm{rpm}$ for $10 \mathrm{~min}$ to obtain serum. The rat serum rheumatoid factor (RF), interferon- $\gamma($ IFN- $\gamma)$, interleukin$1 \beta(\mathrm{IL}-1 \beta)$, interleukin-4(IL-4), interleukin-10 (IL-10), and tumor necrosis factor- $\alpha$ (TNF- $\alpha$ ) were detected by ELISA kits (Jianglai Biological Co., Ltd.,Shanghai, China).

\section{H\&E staining and immunohistochemistry (IHC) staining}

Synovial tissue of the joint from rat was fixed in $4 \%$ paraformaldehyde for $24 \mathrm{~h}$. The tissues were dehydrated with ethanol and xylene, fixed in paraffin and sectioned $(4 \mu \mathrm{m})$ for staining. The synovial tissue of the joint sections was stained with hematoxylin and eosin (H\&E) and the images were acquired under a light microscope equipped with $10 \times$ or $40 \times$ objective lens. For IHC staining, the paraffin sections were deparaffinized with xylene and $3 \%$ hydrogen peroxide for antigen retrieval at room temperature for $10 \mathrm{~min}$. Then, the sections were incubated with primary antibodies against $\operatorname{RAF}(1: 500$; ab125212; Abcam, CA, USA) at $4{ }^{\circ} \mathrm{C}$ overnight, followed by incubation with the appropriate amount of HRP goat anti-rabbit IgG (1:5000; ab205718; Abcam, CA, USA) for $30 \mathrm{~min}$ at $37{ }^{\circ} \mathrm{C}$. Next, the reaction was visualized using $\mathrm{DAB}$ (Boster, Wuhan, China). Five visual fields were randomly selected and assessed for immunoreactive areas at $\times 200$ magnification using BA400Digital microscope (Motic, Xiamen, China). The optical density of image was analysed by Image-Pro Plus software (Media Cybernetics, Inc., Rockville, MD, USA).

\section{Terminal deoxynucleotidyl transferase dUTP nick end labeling (TUNEL) staining}

The tissue from synovium of joint was incubated with proteinase $\mathrm{K}$ at $37^{\circ} \mathrm{C}$ for $30 \mathrm{~min}$ in the dark to make the cell model permeable. $100 \mu \mathrm{L} 1 \times$ Equilibration Buffer was used to fix it for 10-30 min. Then, aspirate the supernatant and incubate it with Alexa Flour 488-dUTP Labeling Mix at $37^{\circ} \mathrm{C}$ for $1 \mathrm{~h}$, wash away the background with PBS, seal the cell slide with DAPI-containing mounting 
tablets, and observe and collect under a laser confocal microscope.

\section{Western blot assay}

Proteins were extracted from MH7A cells, ankle joint and knee joint tissues using RIPA lysis buffer (BeyoTime Biotech, Shanghai, China) and quantified by a BCA Protein Assay Kit (BeyoTime, China). A total of $20 \mu \mathrm{g}$ protein sample was separated by $8 \%$ SDS-PAGE and blotted onto PVDF membrane. After blocked with 5\% non-fat milk in TBST for $1 \mathrm{~h}$ at room temperature, the membranes were then incubated with appropriate primary antibodies at $4{ }^{\circ} \mathrm{C}$ overnight, followed by probed with secondary antibody (Abcam, USA, ab205718) conjugated to horseradish peroxidase. The protein signals were visualized using an ECL detection system. The primary antibodies including RAF (Abcam, USA, ab170099), ERK1/2 (Abcam, USA; ab184699), p-ERK1/2 (Abcam, USA, ab76299).

\section{Cell culture and treatment}

Human rheumatoid arthritis fibroblast-like synoviocyte cell line MH7A was purchased from Procell Life Science \& Technology Co., Ltd. (Wuhan, China). Cells were divided into 4 groups. The blank control cells were cultured as normal. The concentration of GA treatment group is $10 \mu \mathrm{g} / \mathrm{mL}$. RAF overexpression group, the plasmid concentration of pcDNA3.1RAF (Sangon Biotech (Shanghai) Co., Ltd.) was $100 \mu \mathrm{g} / \mathrm{mL}$. The fourth is GA and pcDNA3.1RAF combined treatment group. MH7A cells were cultured in DMEM/high glucose medium (Hyclone, USA) supplemented with 10\% fetal bovine serum (FBS, Gibco, USA) and $1 \%$ glutamine (Sigma, USA) and incubated at $37^{\circ} \mathrm{C}$ under $5 \% \mathrm{CO}_{2}$.

\section{Cell proliferation assay}

Cell Counting Kit-8 (CCK-8) (Dojindo, Japan) assay was used to measure cell proliferation. MH7A cells in logarithmic growth phase were seeded in a 96-well plate $\left(6 \times 10^{3} /\right.$ well $)$. After the cells were attached to the wall, the cells were incubated with GA $(10 \mu \mathrm{g} / \mathrm{mL})$ or pcDNA3.1 RAF plasmid $(100 \mu \mathrm{g} / \mathrm{mL})$ for $48 \mathrm{~h}$, and then the cells were incubated with $10 \%$ CCK- 8 solution for $1 \mathrm{~h}$ at $37{ }^{\circ} \mathrm{C}$ under $5 \% \mathrm{CO} 2$. The absorbance value was measured using a microplate reader under $450 \mathrm{~nm}$.

\section{Apoptosis assay}

Annexin V-APC/PI staining and flow cytometry (FCM) were performed to detect apoptosis of MH7A cells. Cells were double-labeled with Annexin V-APC/PI (Abnova, China) in the dark at room temperature for $15 \mathrm{~min}$. Then, the FACSCalibur flow cytometer of BD Biosciences in the United States was used to analyze the effect of GA on cell apoptosis.

\section{Transwell invasion assay}

$0.25 \%$ trypsin-EDTA solution with a cell density of $2 \times 10^{5} / \mathrm{ml}$ was used for transwell invasion assay. $50 \mu \mathrm{l}$ of Matrigel (BD Biosciences, Franklin Lakes, NJ, USA) was added on the membrane of the upper chamber and solidified at $37{ }^{\circ} \mathrm{C}$ for $30 \mathrm{~min} .600 \mu \mathrm{l}$ of complete medium containing $10 \%$ fetal bovine serum (FBS; Gibco, Grand Island, NY, USA) was added to a 24-well plate, and $100 \mu \mathrm{l}$ of cell suspension was seeded on the membrane and incubated at $37{ }^{\circ} \mathrm{C}$ in an atmosphere of humidified air and $5 \% \mathrm{CO}_{2}$ incubator. Transwells were collected $24 \mathrm{~h}$ after incubation, fixed in $-20^{\circ} \mathrm{C}$ cold methanol for $30 \mathrm{~min}$, and then stained with $0.5 \%$ crystal violet (Solarbio, Beijing, China) at room temperature for $20 \mathrm{~min}$. Invasive cells were observed under an optical microscope (Olympus, Tokyo, Japan). Assays were independently repeated three times.

\section{Statistical analysis}

One-way ANOVA was performed for statistical analysis (SPSS 19.0) Values were presented as the means \pm standard deviation (SD). Differences among multiple groups were compared by one-way analysis of variance (ANOVA) with Dunnett's post-tests The differences were considered statistically significant at $P<0.05$ and $P<0.01$.

\section{Results}

The therapeutic effect of GA on rheumatoid arthritis

GA is a quinonoid phenolic acid synthesized in plants (Fig. 1A). To study the therapeutic effects of GA on RA, the CIA rat model was chosen to be the subject. As shown in Fig. 1B, there was hardly any swelling in the control group. However, joint swelling was observed clearly in the model group. Compared with the model group, the level of joint swelling was alleviated in $30 \mathrm{mg} /$ $\mathrm{kg}$ and $60 \mathrm{mg} / \mathrm{kg}$ GA treatment rats. To prove GA can restore abnormal changes of inflammatory mediators, anti-inflammatory mediators, and rheumatoid factors in serum were detected. As shown in Fig. 1C, D, the levels of INFc, IL-1 $\beta$, TNF- $\alpha$, and rheumatoid factor (RF) in the model group was significantly higher than those in the control group, while the levels of the above-mentioned inflammatory mediators and RF have significantly decreased following GA treatment. The levels of IL-4 and IL-10 in the model group were significantly lower than those in the control group. However, compared with the model group, they were significantly increased in the $30 \mathrm{mg} / \mathrm{kg}$ and $60 \mathrm{mg} / \mathrm{kg} \mathrm{GA}$ treatment groups (Fig. 1D). These results indicated that GA can treat RA by reducing inflammation. 
<smiles>O=C(O)c1cc(O)ccc1O</smiles>

C

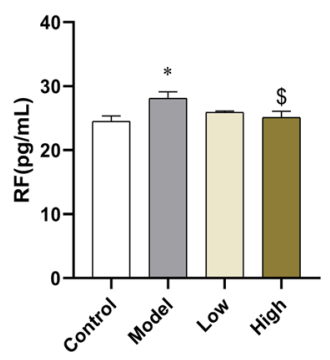

B

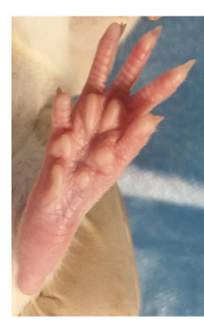

Control

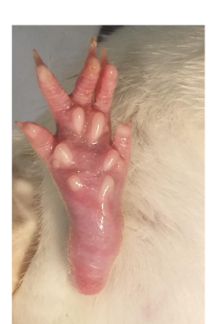

Model

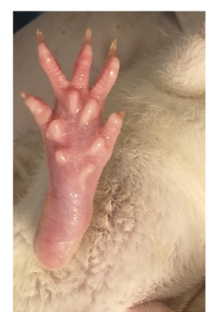

Low

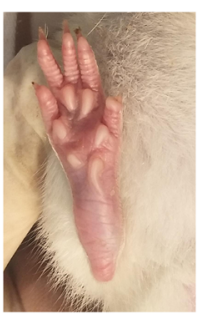

High

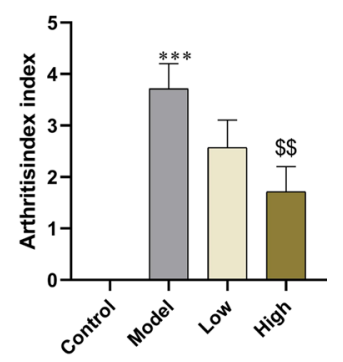

D

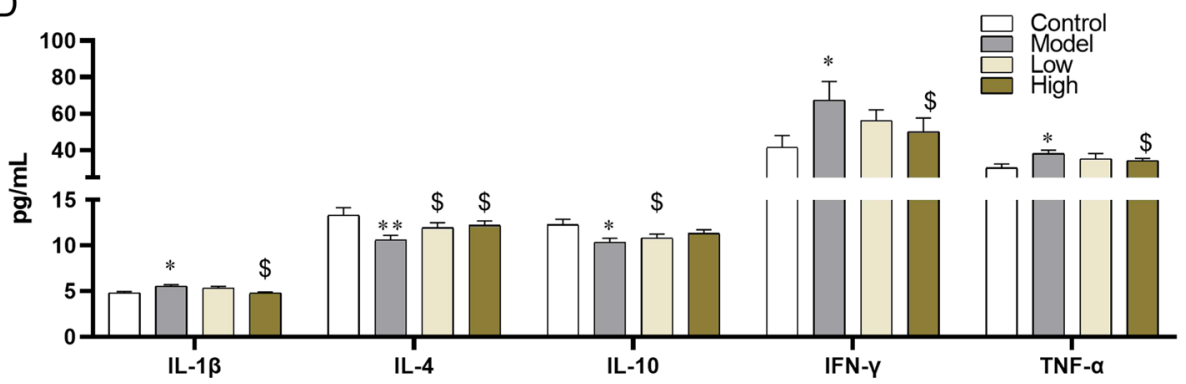

Fig. 1 The therapeutic effect of GA on rheumatoid arthritis. A 2D structure of gentisic acid. B Representative picture of joint swelling in CIA rats. C The effect of GA on serum RF levels. D The effect of GA on serum IFN- $\mathrm{IL}-1 \beta$, TNF- $a$, IL-4, and IL-10 levels. Arthritis index: 0 means no redness and swelling; 1 means little toe joints are slightly swollen and red; 2 means more than one joint is swollen and red; 3 means toe joints and feet are swollen; 4 means ankle joints and feet below the ankle joints The paws are swollen. ${ }^{*} P<0.05,{ }^{*} P<0.01$, and ${ }^{* * *} P<0.001$ compared with the control group. ${ }^{\$} P<0.05$, ${ }^{\$} P<0.01$, and ${ }^{\$ \$} P<0.001$ compared with model group

\section{The effect of GA on histochemical with rheumatoid arthritis}

To determine whether GA restored pathological changes in Synovial Tissue, HE staining was performed on synovial tissue of the ankle and knee joints. As shown in Fig. 2A, the synovial structure of the ankle joint in the control group was clear and complete, with connective tissue composed of more fat cells, a few fibroblasts, macrophages, and a few blood vessels. The synovial tissue had no inflammatory cell infiltration and fibrous tissue hyperplasia. In the model group, the thickness of the synovial lining of the ankle joint was significantly thicker, and more inflammatory cells were infiltrated, including lymphocytes, plasma cells, and a small number of macrophages. Moreover, in the lower layer of the synovial lining, a large number of the proliferation of fibrous tissues can be seen, and the proliferation of fibroblasts with an oblong nucleus can be seen. The above-mentioned adverse reactions were alleviated under GA treatment. As shown in Fig. 2B, the synovial structure of the knee joint in the control group was clear and complete. The lining layer was composed of a single layer or a double layer of synovial cells, and no inflammatory cell infiltration and fibrous tissue hyperplasia. Synovial cells in the model group proliferated significantly, and the lower layer was multi-fibered, and fibroblasts with oval nuclei.
The lower layer is infiltrated with multiple inflammatory cells, including lymphocytes, neutrophils, and macrophages. The adverse reactions caused by BTII under the treatment of low and high doses of GA are close to those of the control group. Apoptotic cells were detected by TUNEL staining (Fig. $2 \mathrm{C}, \mathrm{D}$ ), and the positive cells were stained by Alexa Flour 488-dUTP Labeling Mix as green. The control group and model was no green fluorescence, while the GA treatment group had more green fluorescent cells than the model group. These results indicated that GA can improve synovial hyperplasia and inhibit apoptosis of synovial tissues in CIA rats.

\section{GA inhibited the activation of RAF/ERK1/2 pathway in synovial tissue}

To explore the regulatory mechanism of GA inhibits RA, the RAF/ERK signaling pathway was detected by immunohistochemistry and western blot assays. Compared with the control group, the expression of RAF was significantly increased in the model group. However, the levels of RAF in ankle and knee joints induced by Bovine type II collagen were reversed by GA especially within high dosage (Fig. 3A, B). At the same time, Phosphorylation of ERK1/2 was significantly increased in the model group, almost twofold compared to the 


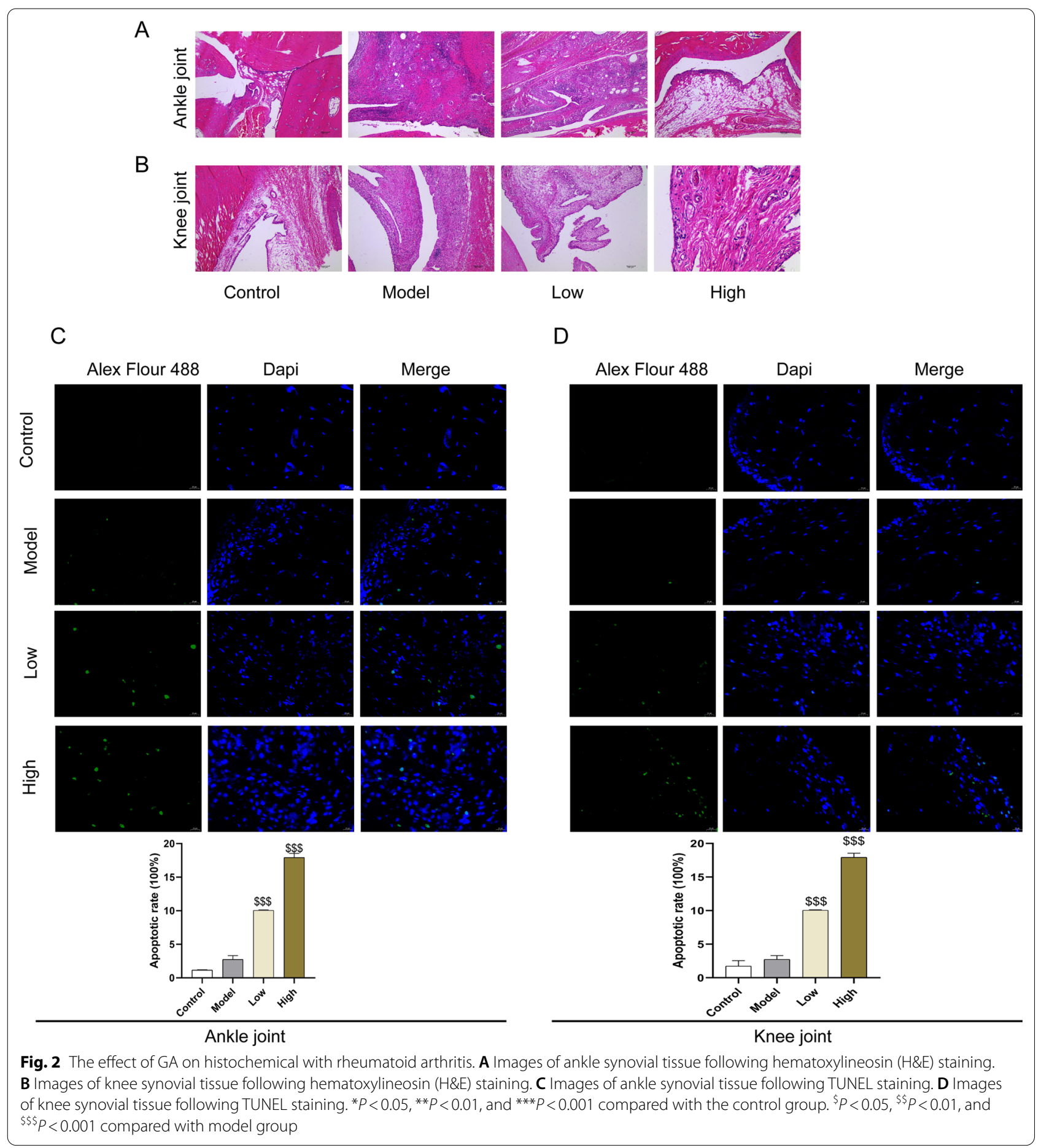

control group, while it was significantly decreased in each dose of the GA treatment group (Fig. 3C, D). This result indicated that the RAF/ERK1/2 signaling pathway was activated in CIA rats, and can be reversed by the high concentration of GA.

\section{The biological effects of RAF/ERK1/2 pathway on MH7A} cells

To further investigate the effect of GA on MH7A cells damage is through activation of the RAF/ERK1/2 pathway, MH7A cells were transfected with pcDNA3.1 RAF plasmid and detected by, CCK8, Transwell invasion, 
A

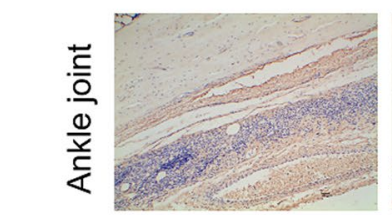

B

Control

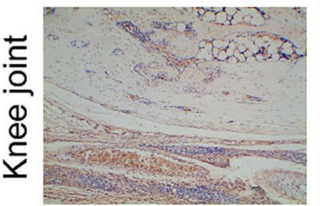

Control

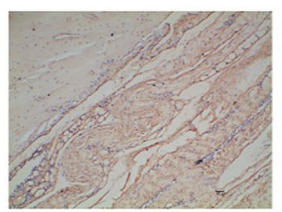

Model

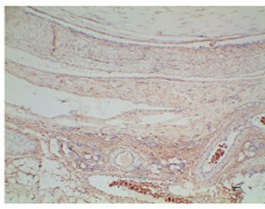

Model

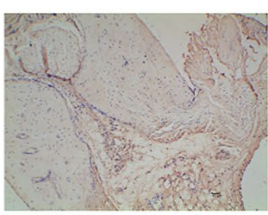

Low

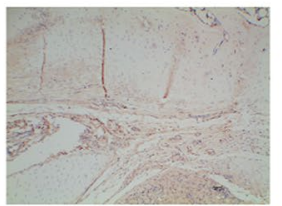

Low

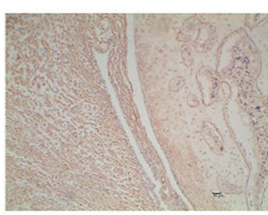

High

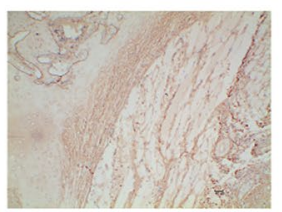

High

C
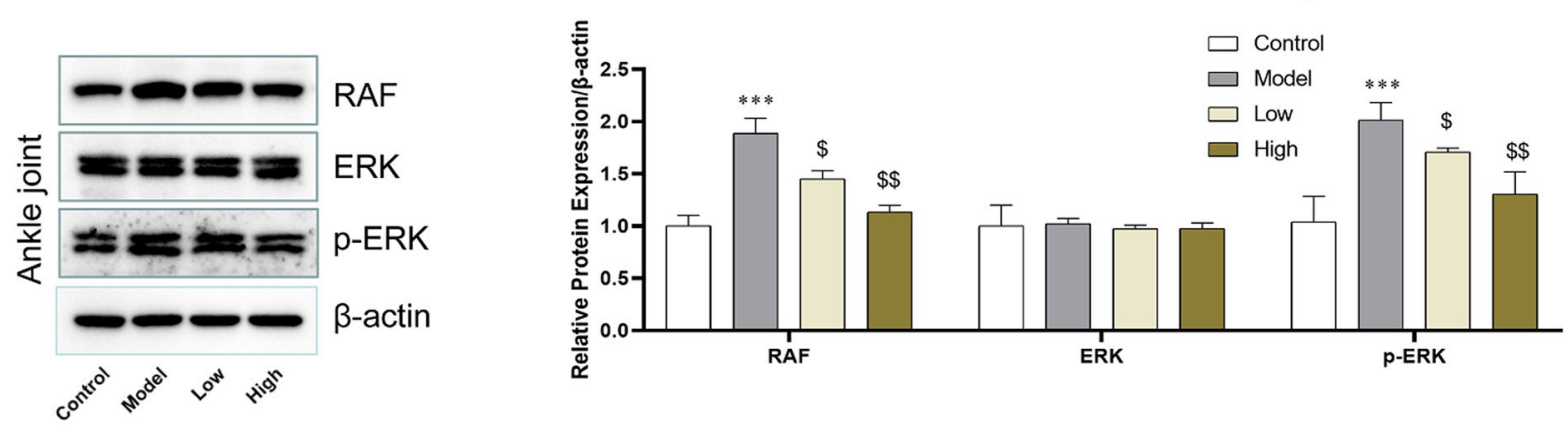

D
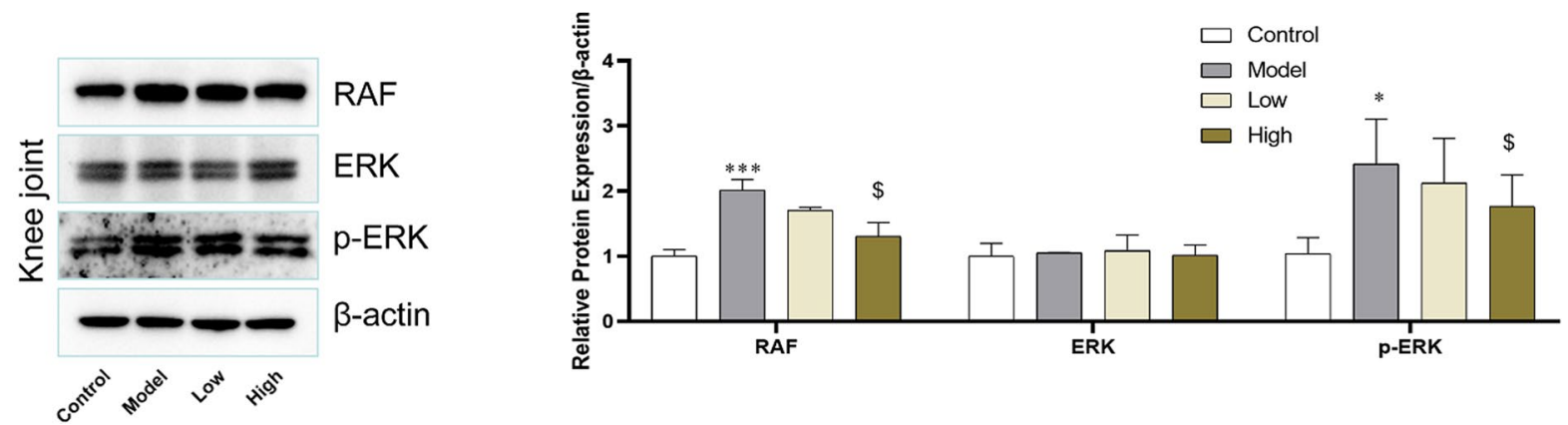

Fig. 3 RAF, p-ERK1/2, and ERK1/2 protein levels in synovial tissue of ankle joint and knee joint. A Immunohistochemical analysis of RAF in ankle synovial. B Immunohistochemical analysis of RAF in knee synovial. C The effect of GA on the expression of RAF, ERK, and p-ERK in ankle synovial. D The effect of GA on the expression of RAF, ERK, and p-ERK in knee synovial. ${ }^{*} P<0.05,{ }^{*} P<0.01$, and ${ }^{* *} P<0.001$ compared with the control group. $\$ P<0.05,{ }^{\$} P<0.01$, and ${ }^{\$ \$} P<0.001$ compared with model group

and FCM assays. The optimal concentration of $10 \mu \mathrm{g} /$ $\mathrm{mL}$ was obtained through preliminary experiments. Compared with the control group, overexpressed RAF by pcDNA3.1RAF has the effect of promotes cell proliferation and inhibits apoptosis. GA can reduce the high expression of RAF, which can further affect the increase in cell proliferation and the decrease in apoptosis caused by overexpression of RAF (Fig. 4A, D). As shown in Fig. 4C, GA can inhibit cell invasion, while overexpressed
RF has the opposite effect. To further testify the signal transduction pathway of GA, a western blot assay was performed to detect the expression of RAF/ERK in MH7A cells (Fig. 4B). Compared with the control group, pcDNA3.1RAF can significantly overexpress RAF. GA can inhibit the expression of protein RAF and p-ERK, while pcDNA3.1RAF can promote the expression of RAF and even p-ERK, so the activation of RAF can further activate ERK (Fig. 4C). These data indicated that 


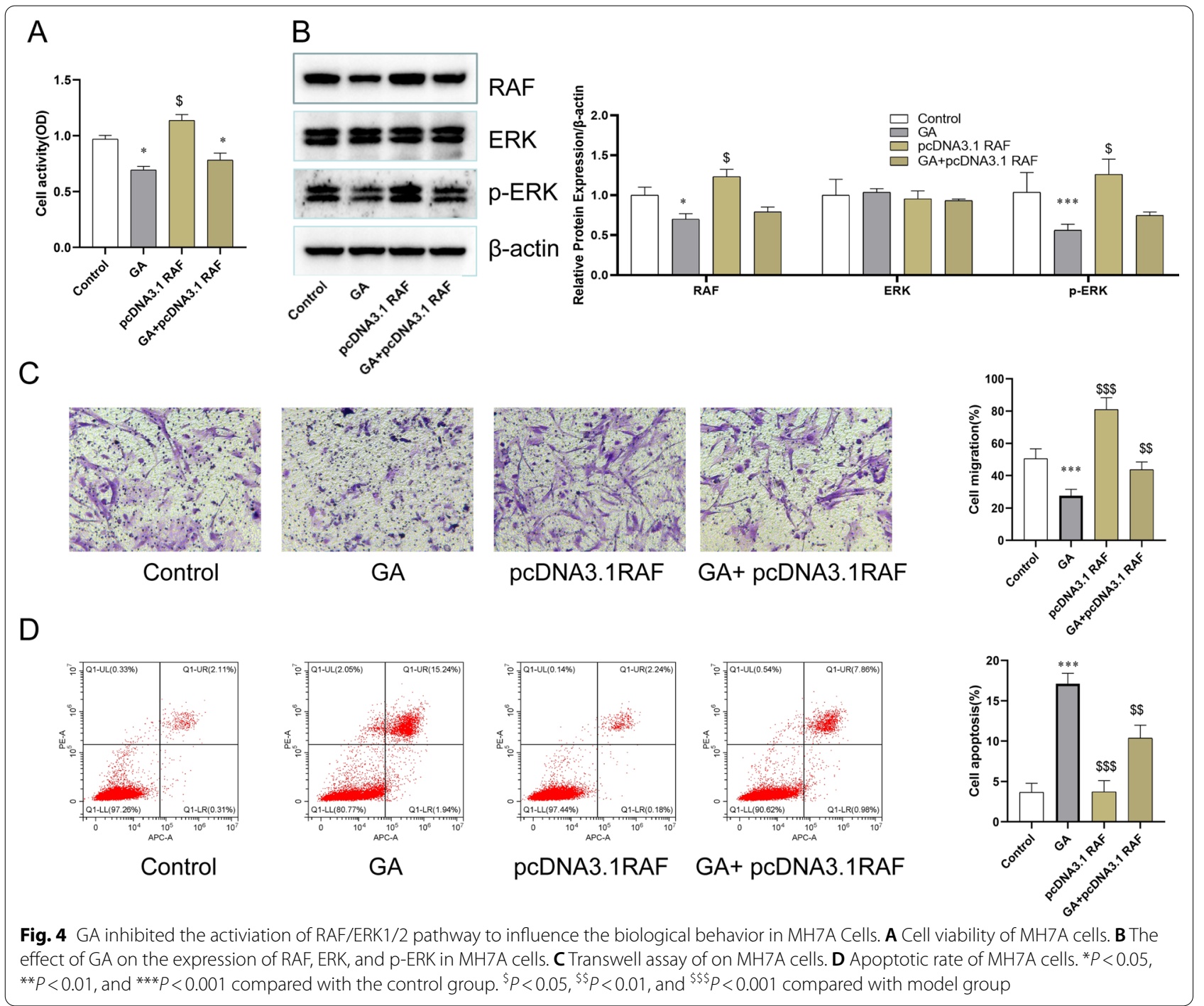

GA could inhibit cell viability and promote apoptosis in MH7A cells via RAF/ERK1/2 pathway.

\section{Discussion}

With the continuous improvement of living standards of Chinese residents and the increasing pressure of work and life, the number of patients with RA is increasing.

The Miao, Bai, and Yi ethnic minorities in my country have experience in applying TGX has significant effects in the treatment of muscle soreness, rheumatism, lumbar spine hyperostosis, ankle sprain, and rheumatic arthralgia [18]. In this study, we demonstrated the effect of gentisic acid on CIA model rats through RAF/ERK pathway and verified it again in RA-FLS cells for the first time. We confirmed that GA could alleviate systemic inflammation, synovial hyperplasia, and MH7A cell proliferation.
We also find that GA can influence the invasiveness of RA-FLS.

It's well known, serum inflammatory factors and rheumatoid factors are important characteristicss of rheumatoid arthritis. Many studies have demonstrated that TNF- $\alpha$, IFN- $\gamma$, and IL- $1 \beta$ in the peripheral blood of RA of patients are significantly increased $[19,20]$. The reduction of a variety of anti-inflammatory factors in serum accelerates the pathological process of the disease, including IL-4 and IL-10 [21, 22]. The increase of RF in the model group proved that the CIA model prepared during the experiment was successful, and could be reversed high-dose of GA. The results of this study also showed that GA can inhibit TNF- $\alpha$, IFN- $\gamma$, and IL-1 $\beta$ caused by BTII, and it can also inhibit the down-regulation of IL-4 and IL-10 caused by BTII. The therapeutic effect of the high-dose group is particularly 
obvious, suggesting that the therapeutic effect of GA on CIA rats may be through regulating inflammatory factors and RF directly. Regarding H\&E and TUNEL staining experiments, we found that the inflammation and synovial hyperplasia of synovial tissue in CIA rats were improved after GA was administered. In addition, the administration of GA also promoted synovial cell apoptosis. The above results indicated that GA has the effect of inhibiting the proliferation of rheumatoid arthritis synovial cells, and the therapeutic effect of the drug may be achieved by promoting cell apoptosis.

RAF and ERK are the two key proteins in the MAPK signaling pathway, and the MAPKs pathway is the critical signaling pathway in the pathogenesis of RA $[23,24]$. The Muller-Ladners' study showed that when MAPKs were activating, the proliferation ability of RAFLS became strong [25]. Zhangs' experiment proved that overexpression of Spry2 could attenuate the proliferation of Raf/ERK pathway and RA FLSs $[11,26]$. In this research, the results of immunohistochemistry and western blot showed that RAF and ERK were highly expressed in rat joint synovium tissues, and they could be activated by COII. At the same time, GA had a significant inhibitory effect on the expression of Raf and ERK proteins. Therefore, GA seems to have an inhibitory effect on the expression of Raf and ERK proteins, indicating that the GA may inhibit the RAF/ERK1/2 pathway to achieve the therapeutic effect of RA.

Additionally, GA has an inhibitory effect on RA-FLS through the RAF/ERK pathway. The results showed that GA could inhibit the biological behavior of MH7A, such as proliferation and invasion. The result of Flow cytometry experiments showed that the activation of RAF has the effect of inhibiting cell apoptosis. The result of western blot showed that compared with the control group, GA could inhibit the expression of protein RAF and p-ERK. While, pcDNA3.1RAF can promote RAF, and the activation of the RAF can further activate ERK. These experimental results show that RAF can activate ERK and affect the proliferation of RA-FLS, and RAF may be a potential target for RA treatment.

\section{Conclusions}

GA significantly inhibits joint inflammation by regulating Raf/ERK signals, suggesting that GA-based immunomodulation strategies may have therapeutic potential in the treatment of RA. At the same time, GA can also inhibit the proliferation of RA-FLS and promote apoptosis to achieve the purpose of treating RA through the Raf/ERK pathway.
Abbreviations

GA: Gentisic acid; RA: Rheumatoid arthritis; FLS: Fibroblast-like synoviocytesl; TGX: Touguxiang; BTIl: Bovine type II collagen.

\section{Authors' contributions}

XjD fnished the experiment, collected and analyzed data, and wrote a frst draft, DD assisted in analyzing the data and revising the manuscript. QZ, $F Z$, and $M \times C$ read and approved the fnal manuscript. All authors read and approved the final manuscript.

\section{Funding}

The present study was supported by the Zunyi Science and Technology Bureau (No. [2019]194).

Availability of data and materials

Not applicable.

\section{Declarations}

Human and animal rights

The animal experiment was approved by the Ethics Committee of the Afliated Hospital of Zunyi Medical and Pharmaceutical College and complied with the regulations of China's "Guidelines for the Feeding, Management and Use of Laboratory Animals".

\section{Consent for publication}

All authors were published with their informed consent.

\section{Competing interests}

The authors declare that they have no competing interests.

Received: 18 December 2021 Accepted: 9 February 2022

Published online: 20 February 2022

\section{References}

1. Firestein GS. Evolving concepts of rheumatoid arthritis. Nature. 2003:423(6937):356-3616

2. Grennan DM, Sanders PA. Rheumatoid arthritis. Baillieres Clin Rheumatol. 1988;2(3):585-601.

3. Cross M, Smith E, Hoy D, Carmona L, Wolfe F, Vos T, et al. The global burden of rheumatoid arthritis: estimates from the Global Burden of Disease 2010 study. Ann Rheum Dis. 2014;73(7):1316-22.

4. Bombardier C, Barbieri M, Parthan A, Zack DJ, Walker V, Macarios D, et al. The relationship between joint damage and functional disability in rheumatoid arthritis: a systematic review. Ann Rheum Dis. 2012;71(6):836-44.

5. Nah SS, Won HJ, Ha E, Kang I, Hong YC, Hur SJ, et al. Epidermal growth factor increases prostaglandin E2 production via ERK1/2 MAPK and NF-KB pathway in fibroblast like synoviocytes from patients with rheumatoid arthritis. Rheumatol Int 2010;30(4):443-9.

6. Huber LC, Distler O, Tarner I, Gay RE, Pap T. Synovial fibroblasts: key players in rheumatoid arthritis. Rheumatology. 2006;45(6):669-75.

7. Liu Q, Xiao XH, Hu LB, Jie HY, Ying W, Ye WC, et al. Anhuienoside C Ameliorates Collagen-Induced Arthritis through Inhibition of MAPK and NF-KB Signaling Pathways. Front Pharmacol. 2017;8:299.

8. Bartok B, Firestein GS. Fibroblast-like synoviocytes: key effector cells in rheumatoid arthritis. Immunol Rev. 2010;233(1):233-55.

9. Okamoto H, Shidara K, Hoshi D, Kamatani N. Anti-arthritis effects of vitamin K(2) (menaquinone-4) - a new potential therapeutic strategy for rheumatoid arthritis. FEBS J. 2007;274(17):4588-94.

10. Nishimura K, Sugiyama D, Kogata Y, Tsuji G, Nakazawa T, Kawano S, et al Meta-analysis: diagnostic accuracy of anti-cyclic citrullinated peptide antibody and rheumatoid factor for rheumatoid arthritis. Ann Intern Med. 2007;146(11):797.

11. Zhang W, Du Z, Zhu J, Yu J, Xu Y. Sprouty2 suppresses the inflammatory responses in rheumatoid arthritis fibroblast-like synoviocytes through regulating the Raf/ERK and PTEN/AKT signals. Mol Immunol. 2015;67:532-9. 
12. Guanling $X$, Tian Y, Xie M, Yang Y, et al. The anti-rheumatoid arthritis property of the folk medicine Dianbaizhu (Gauhheria leucocarpa var. yunnanensis, Ericaceae). Nat Prod Commun. 2014;9(12):1773-6.

13. Yingkang C, Fuqiang S, Dateng L, Jianchao Z, Yan L, Peiyan T. Experimental study on the effect of Miao medicine Touguxiang on acute gouty arthritis. J Chin Med Mater. 2016;39(09):2118-21.

14. Zeng $Y$, Tang $Z$, Wang $Q$, He $P$, Fang $Y$. Simultaneous determination of active ingredients in ethnomedicine Gaultheria leucocarpa var. yunnanensis and its medicinal preparation by capillary electrophoresis with electrochemical detection. J Chromatogr Sci. 2007;9:610-5.

15. Sun S, Kee HJ, Jin L, Ryu Y, Choi SY, Kim G, et al. Gentisic acid attenuates pressure overload-induced cardiac hypertrophy and fibrosis in mice through inhibition of the ERK1/2 pathway. J Cell Mol Med. 2018;22:5964-77.

16. Wang K, Zhang D, Liu Y, Wang X, Zhao J, Sun T, et al. Traditional Chinese medicine formula Bi-Qi capsule alleviates rheumatoid arthritis-induced inflammation, synovial hyperplasia, and cartilage destruction in rats. Arthritis Res Ther. 2018;20(1):43.

17. Dong $X$, Gan Y, Ding L, Zeng F, Ding D. Effect of Jiawei fengshining on synovial cell apoptosis and TGF- $\beta 1 /$ Smad signaling pathway in rats with rheumatoid arthritis. Evid Based Complement Alternat Med. 2019;2019:8614034.

18. Coderre TJ, Wall PD. Ankle joint urate arthritis in rats provides a useful tool for the evaluation of analgesic and anti-arthritic agents. Pharmacol Biochem Behav. 1988;29(3):461-6.

19. Jeong J-G, Kim J-M, Cho H, Hahn W, Yu SS, Kim S. Effects of IL-1 $\beta$ on gene expression in human rheumatoid synovial fibroblasts. Biochem Biophys Res Commun. 2004;324:3-7.

20. Brennan FM, Mcinnes IB, Brennan FM, McInnes IB. Evidence that cytokines play a role in rheumatoid arthritis. J Clin Investig. 2008;1 18(11):3537-45.

21. Brentano F, Kyburz D, Schorr O, Gay R, Gay S. The role of Toll-like receptor signalling in the pathogenesis of arthritis. Int I Intern Med. 2005;233(2):90-6.

22. Barati A, Jamshidi AR, Ahmadi H, Aghazadeh Z, Mirshafiey A. Effects of beta-D-mannuronic acid, as a novel non-steroidal anti-infla | DDDT. 2017.

23. Roskoski R, Roskoski R Jr. ERK1/2 MAP kinases: structure, function, and regulation. Pharmacol Res. 2012;66(2):105-43.

24. Wang X, Li F, Fan C, Wang C, Ruan H. Effects and relationship of ERK 1 and ERK2 in interleukin-1 $\beta$-induced alterations in MMP3, MMP13, type II collagen and aggrecan expression in human chondrocytes. Int J Mol Med. 2011;27(4):583-9.

25. Müller-Ladner U, Gay ER. Activation of synoviocytes. Curr Opin Rheumatol. 2000;12:186-94.

26. Zhang W, Zhu J, Du Z, et al. Intraarticular gene transfer of SPRY2 suppresses adjuvant-induced arthritis in rats. Appl Microbiol Biotechnol. 2015;99:6727-35

\section{Publisher's Note}

Springer Nature remains neutral with regard to jurisdictional claims in published maps and institutional affiliations.

Ready to submit your research? Choose BMC and benefit from:

- fast, convenient online submission

- thorough peer review by experienced researchers in your field

- rapid publication on acceptance

- support for research data, including large and complex data types

- gold Open Access which fosters wider collaboration and increased citations

- maximum visibility for your research: over $100 \mathrm{M}$ website views per year

At BMC, research is always in progress.

Learn more biomedcentral.com/submissions 